\title{
Sources and history of PAHs in lake sediments from oil-producing and industrial areas, northeast China
}

\author{
L. Sun $\cdot$ S. Y. Zang $\cdot$ H. J. Sun
}

Received: 28 August 2013/ Accepted: 9 October 2013/Published online: 30 October 2013

(C) Islamic Azad University (IAU) 2013

\begin{abstract}
Abundance, sources, and historical records of polycyclic aromatic hydrocarbons (PAHs) in sediment cores of three lakes located in northeast China were evaluated. One lake was located in a rural oil field area, one in an industrial urban oil field area, and the third in an urban industrialized area without oil field influence. Cores from each lake were divided into $1-\mathrm{cm}$ sections, dated using ${ }^{137} \mathrm{Cs}$ techniques, and 16 priority $\mathrm{PAH}$ compounds were measured. Total PAH concentrations were greater in industrial areas than in rural area, regardless of associated oil production. Only petroleum sources of PAHs were identified in lakes near oil fields between 1950s and 1980s, while sources of liquid fossil fuel combustion were persistently identified in the industrial urban lake. From 1990s to 2000s, PAH concentrations, especially high molecular weight PAHs, significantly increased in all lakes, which were consistent with the economic development in China, suggesting a change in energy use from wood burning and petroleum (oil) to liquid fossil fuel combustion. Environmental risk was low to moderate in sediments of the three lakes studied, and increases in high molecular weight PAHs during 1900s-2000s is a concern.
\end{abstract}

Keywords Polycyclic aromatic hydrocarbons · Core sediments · Diagnostic ratios · Pollution history · Oil field

L. Sun $\cdot$ S. Y. Zang $(\bowtie) \cdot$ H. J. Sun

Key Laboratory of Remote Sensing Monitoring of Geographic Environment, College of Heilongjiang Province, Harbin Normal University, No. 1 South Shida Road, Limin Economic Development Zone, Harbin 150025, Heilongjiang, People's Republic of China

e-mail: zsy6311@163.com

\section{Introduction}

Although oil exploitation promotes local economic development, it may also generate huge amount of contaminants such as sulfur dioxide $\left(\mathrm{SO}_{2}\right)$, nitrogen oxide ( $\left.\mathrm{NOx}\right)$, and polycyclic aromatic hydrocarbons (PAHs) (Rao et al. 2008). Among the contaminants, PAHs are the dominant one found in petroleum manufacturing process that may be released during drilling, transportation, and extraction processes of crude and refined oil (Sun et al. 2011; Froehner et al. 2012a, b; Inengite et al. 2013). Due to their toxic, carcinogenic, and mutagenic characteristics (Salam et al. 2011; Froehner et al. 2012a, b; Liu et al. 2012), released petroleum may pose a risk to the terrestrial and aquatic ecosystems, including human health (Rao et al. 2008; Kumar and Kothiyal 2011). In general, PAHs as a large group of hazardous substances can originate via natural, domestic, and industrial activities including natural fires, plant emissions, combustion of fossil fuels, incomplete combustion of organic matter, and vehicle exhausts (Countway et al. 2003; Hu et al. 2010; Zhao et al. 2012a, b). Accordingly, because of the influences of human activities, PAH concentrations and sources may be different between industrial urban area and agriculture rural area. Hence, an understanding of the impact of petroleum-related activities and different anthropogenic activities on PAHs is undoubtedly of great importance.

Once released, PAHs in the environment eventually accumulate in soils and aquatic sediments by atmospheric transport or via overland runoff. Thus, sediments can be considered as one of the pollution sinks (Liu et al. 2009; Froehner et al. 2012a, b). In lake sediments, when PAHs accumulate in the food web, there is a potential for harmful damaging effects on wildlife and human health (Liu et al. 2009). Studies of sediment records can thus provide 
information on levels, history, and trends of PAH pollutants in aquatic environments. Although sources of PAH contamination have been extensively studied in recent years (Luo et al. 2008; Zhao et al. 2012b), few surveys have been conducted to comparatively assess the influences of oil exploitation on the environment, and differences in PAH sources from anthropogenic activities in different regions.

The primary objective of the current study was to determine whether the processes of oil exploitation and development can release PAHs that may pose ecological risk, and identify differences in sources of PAHs between rural and industrial areas. Our specific objectives were to (1) evaluate the concentrations of PAHs in three lake sediment cores, (2) identify differences and similarities in sources and pollution histories of PAHs in lakes with different surrounding land uses, and (3) evaluate potential human and environmental risks of PAHs and compare results between oil development areas and industrial areas.

\section{Materials and methods}

Study area and sample collection

Polycyclic aromatic hydrocarbons in sediment cores from the three lakes in the western region of the Songnen Plain, Heilongjiang Province, northeast China, were evaluated. Two lakes were adjacent to oil fields located within the Daqing Oil Field: Lianhuan (LH) Lake located near the City of Daqing and Wanghua (WH) Lake located in a rural area. The third lake, Keqin (KQ) Lake, was near the City of Qiqihar, a highly developed industrial city, but not associated with an oil field.

During July 2007, three sediment cores were collected from the central and deepest area of each lake using a stainless steel static gravity piston corer. The core sediments were immediately sectioned at $1-\mathrm{cm}$ intervals and transported on ice to the laboratory where they were stored at $-18{ }^{\circ} \mathrm{C}$ until analysis. The sectioning tool was cleaned using lake water following each section collection. In each lake, the core was used for PAH analysis and sediment dating $\left({ }^{137} \mathrm{Cs}\right.$ analyses). The length of the cores used for $\mathrm{PAH}$ analysis from $\mathrm{LH}, \mathrm{WH}$, and $\mathrm{KQ}$ lakes was 38,25 , and $51 \mathrm{~cm}$, respectively.

\section{Analytical methods}

Sediment core sections were dated at the Nanjing Institute of Geography and Limnology, Chinese Academy of Sciences, Nanjing, China, using ${ }^{137}$ Cs activity. The assay was performed by gamma spectrometry, using a hyper-pure
Germanium detector and Ortec919 controller (EG\&G Ortec, US) with a 16-K multichannel analysis system.

Sixteen PAHs identified by the United States Environmental Protection Agency (US EPA) as priority pollutants were analyzed by the Heilongjiang Environmental Monitoring Centre, Harbin, China, including naphthalene (Nap), acenaphthylene (Acey), acenaphthene (Ace), fluorine (Flu), phenanthrene (Phe), anthracene (Ant), fluoranthene (Fla), pyrene (Pyr), chrysene (Chr), benzo[a]anthracene (BaA), benzo[b]fluoranthene $(\mathrm{BbF})$, benzo[k]fluoranthene $(\mathrm{BkF})$, benzo[a]pyrene (BaP), indeno[1,2,3-cd]pyrene (IcdP), dibenzo[a,h]anthracene (DahA), and benzo[g,h,i]pyrene (BghiP).

Sample extraction and cleanup followed USEPA Method 3540C and Method 3630C (USEPA 1996). The 16 PAHs were extracted using hexane/acetone $(1: 1, \mathrm{v} / \mathrm{v})$ solution in an accelerated solvent system at a pressure of $1,500 \mathrm{psi}$ and $100{ }^{\circ} \mathrm{C}$. Extracted samples were reduced to $1 \mathrm{ml}$ using nitrogen stream, and PAH concentrations were measured using GC/MS in the SIM mode. Method blanks, reagent blanks, and triplicate spiked blanks were analyzed as quality control measures. The surrogate recoveries in all sediment samples were $44-65 \%$ for naphthalene- $d_{8}$, $75-86 \%$ for acenaphthene- $d_{10}, 85-104 \%$ for phenanthrene- $d_{10}, 87-99 \%$ for chrysene- $d_{12}$, and $88-104 \%$ for perylene- $d_{12}$. The detection limit (DL) for PAHs was $1-16 \mathrm{ng} / \mathrm{g}$ dry weight, and sample concentrations were corrected using surrogate recoveries. The mean PAH concentrations for every 10 years from the 1950 s to the 2000 s were evaluated to compare histories of $\mathrm{PAH}$ concentrations in the three core sediments.

Table 1 Risk assessment guideline values of effects range low (ERL) and effects range median (ERM) for PAHs in sediments (ng/g)

\begin{tabular}{lcr}
\hline PAHs & ERL & ERM \\
\hline Nap & 160 & 2,100 \\
Acey & 16 & 500 \\
Ace & 44 & 640 \\
Flu & 19 & 540 \\
Phe & 240 & 1,500 \\
Ant & 85.3 & 1,100 \\
Fla & 600 & 510 \\
Pyr & 665 & 2,600 \\
BaA & 261 & 1,600 \\
Chr & 384 & 2,800 \\
BbF & 320 & 1,880 \\
BkF & 280 & 1,620 \\
BaP & 430 & 1,600 \\
DahA & 63.4 & 260 \\
BghiP & 430 & 1,600 \\
\hline
\end{tabular}


Statistical analysis

Statistical analyses were performed using SPSS version 11.5 (SPSS Inc, USA), and all data were expressed as mean $( \pm \mathrm{SE})$. The concentrations of $16 \mathrm{PAHs}$ in core sediments from the same time period were compared between the three lakes using one-way ANOVA with significance set at $5 \%$ probability level.

\section{Ecological risk assessment}

The threshold effects concentrations, effects range low (ERL) and effects range median (ERM) values for individual PAHs, are applied to assess the ecological toxicity of individual PAH concentrations in sediments (Long et al. 1995; Hakan et al. 2004) (Table 1). If the ERL was exceeded, adverse biological effects were expected occasionally associated with the PAH contamination. If the ERM was exceeded, adverse biological effects were frequently associated with the PAH contamination.

\section{Diagnostic ratios of PAHs}

Based on characteristics such as PAH composition and distribution pattern, diagnostic ratios of individual $\mathrm{PAH}$ compounds were used to distinguish the sources of anthropogenic PAHs. Anthropogenic PAH sources were mainly derived from combustion processes and the spillage of petroleum or its products (Zhao et al. 2012a, b). In the current study, $\mathrm{Fla} /(\mathrm{Fla}+\mathrm{Pyr})$ and $\mathrm{BaA} /(\mathrm{BaA}+\mathrm{Chr})$ ratios were applied to provide information on the source recognition (Hu et al. 2010). In general, a ratio of Fla to $(\mathrm{Fla}+\mathrm{Pyr})<0.4$ indicates petroleum input, ratio between 0.4 and 0.5 suggests liquid fossil fuel (vehicle and crude oil) combustion, and ratio $>0.5$ implies grass, wood, or coal combustion; ratio of $\mathrm{BaA}$ to $(\mathrm{BaA}+\mathrm{Chr})<0.2$ indicates petroleum source, ratio between 0.2 and 0.35 indicates mixed origin, and ratio $>0.35$ is consistent with combustion origin.

\section{Results and discussion}

The current study evaluated the history of anthropogenic sources of PAHs in sections of core sediments collected from the three lakes with different surrounding land uses in Heilongjiang Province, China. Wanghua (WH) Lake was in a rural area of an oil-producing region, Lianhuan (LH) Lake was in an urban industrialized area of an oil-producing region, and Keqin (KQ) Lake was in an urban industrialized area without oil production.

\section{Dating of the sediment cores}

Aging results, using the ${ }^{137} \mathrm{Cs}$ assay, indicated the three cores dated from 1929, 1828, and 1953-2006 in LH, KQ, and WH lakes, respectively. Concentrations of PAHs in $\mathrm{LH}$ and KQ lakes were only analyzed in the sediment cores from 1953 to 2006 to correspond with the dating of WH Lake. Therefore, the PAH concentrations in the three sediment cores corresponded with the historical time period ranging from the 1950 s to the 2000s.

\section{Concentrations and pollution levels of PAHs} in the three lakes

Mean concentrations (range) of total PAHs were 767 (293-2,247), 694 (215-1,308), and 223 (140-363) ng/g dry weight in sediment cores of $\mathrm{LH}, \mathrm{KQ}$, and WH lakes, respectively. There was no significant difference in mean total PAH concentrations between LH and KQ lakes from the 1950s to the 2000s, which were in urban industrialized areas (Fig. 1). However, significantly lower concentrations of total PAHs were measured in the core sediments

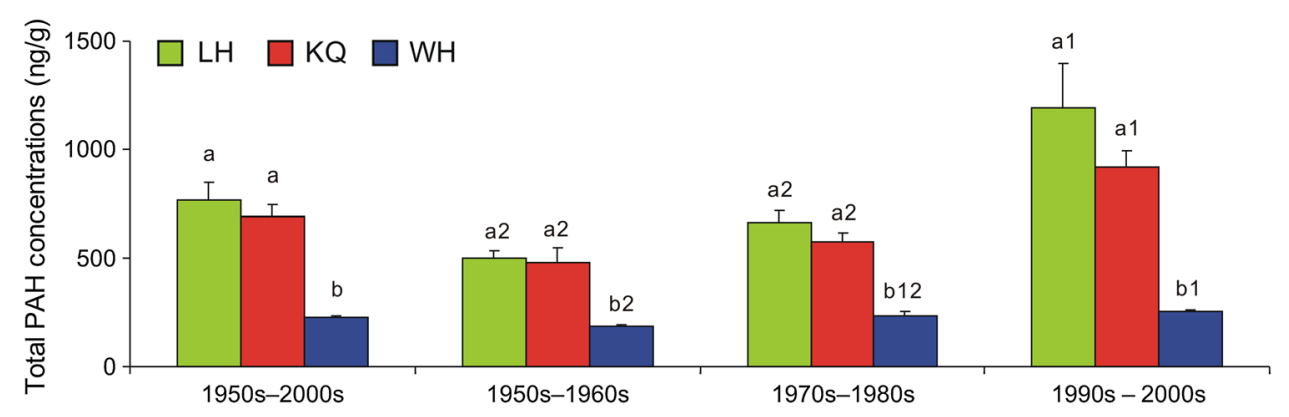

Fig. 1 Mean concentrations (ng/g) of total PAHs in the core sediments from Lianhuan (LH) Lake, Keqin (KQ) Lake, and Wanghua (WH) Lake, Heilongjiang, China, during the time periods of 1950s-2000s, 1950s-1960s, 1970s-1980s, and 1990s-2000s (different letters over the bars indicate a significant difference between the three lakes in the time periods of 1950s-2000s, 1950s-1960s, 1970s-1980s, and 1990s-2000s, respectively; different numbers indicate a significant difference between the three time periods 1950s-1960s, 1970s-1980s, and 1990s-2000s in LH, KQ, and WH lakes, respectively) 
Table 2 Concentrations of PAHs from lake sediments in China compared with the present study

\begin{tabular}{lll}
\hline Locations & $\sum$ PAHs (ng/g dw) & Reference \\
\hline Hongfeng Lake & $>4,500$ & Guo et al. (2011) \\
Taihu Lake & $209-3,843$ & Zhang et al. (2011) \\
Nansi Lake & $160-32,600$ & Li et al. (2009) \\
Mai Po Inner Deep Bay & $102-209$ & Zhao et al. (2012b) \\
Yellow Sea & $45-203$ & Liu et al. (2012) \\
South China Sea & $30-80$ & Liu et al. (2012) \\
LH Lake (northern part) & $297-1,327$ & Sun et al. (2011) \\
LH Lake (southern part) & $198-1,056$ & Sun and Zang (2012) \\
LH Lake (central part) & $293-2,247$ & This study \\
KQ Lake & $215-1,308$ & This study \\
WH Lake & $140-363$ & This study \\
\hline
\end{tabular}

collected from WH Lake located in a rural oil-producing area $(p<0.05)$ (Fig. 1).

The greatest concentrations of PAHs were measured in the sediment core collected from LH Lake, followed by the sediment core from KQ Lake, which were similar to the concentrations measured in sediment core samples collected from the northern and southern parts of LH Lake (Sun et al. 2011; Sun and Zang 2012) (Table 2). Total PAH concentrations measured in the current study were considerably less than in core sediments from Lake Hongfeng, China, which was heavily contaminated by large amounts of urban and industrial activities (Guo et al. 2011) (Table 2). The relatively lower concentrations measured in the core sediments collected from WH Lake were comparable to the concentrations measured in the core sediments collected from the Yellow Sea (Liu et al. 2012) and Mai Po Inner Deep Bay of Hong Kong (Zhao et al. 2012b), lower than the concentrations measured in Lake Nansi, China ( $\mathrm{Li}$ et al. 2009), and greater than the concentrations measured in the South China Sea (Liu et al. 2012) (Table 2). Hence among the three lakes, the two in industrial regions had the greatest concentrations of PAHs and were in moderate pollution levels with greater environmental risk compared to the lake from the rural oil-producing region which was in low pollution level.

In the three core samples, Phe was the most prevalent $\mathrm{PAH}$ compound, followed by Flu, Nap, Fla, and Pyr (Table 3). Contributions of BkF, BaP, DahA, BghiP, DahA, and Acey were relatively low, and concentrations of $\mathrm{BkF}$ were not detected in most of the samples. For historical comparison, the core sediments were divided into three time periods, 1950s-1960s, 1970s-1980s, and 1990s2000s. The mean concentrations of most PAH compounds were significantly different $(p<0.05)$ between the three core sediments during the three time periods (Table 3). For the time period 1950s-1960s, the ranking of mean concentrations of most high molecular weight (HMW) PAHs between the three lakes was KQ $>$ LH $>$ WH Lake. However, ranking of mean concentrations of most low molecular weight (LMW) PAHs varied between the three lakes. Mean concentrations of Phe, Ant, and DahA were not significantly different between the three lakes during this time period.

During 1970s-1980s, mean concentrations of Fla, BaP, IcdP, and DahA in WH and LH lakes were significantly lower than mean concentrations in KQ Lake. For the time period 1990s-2000s, the ranking of mean concentrations of majority of PAH compounds between the three lakes was consistent with that found in the period 1970s-1980s, except that there was no significant difference in mean concentrations of BkF between the three lakes (Table 3).

In general, from 1950s to 2000s, the lowest concentrations of the $16 \mathrm{PAH}$ compounds measured in sediment core samples were found in WH Lake, which was in a rural area, while concentrations of most LMW PAH compounds (Nap, Acey, Ace, Flu, Phe, and Ant) were greater in the sediments of LH Lake, which was associated with an oil field compared to KQ Lake, and concentrations of most HMW PAH compounds (Fla, Pyr, BaA, Chr, BbF, BaP, IcdP, DahA, and BghiP) were greater in KQ Lake sediments compared to LH Lake, as a result of that KQ Lake was near a highly developed industrial city.

\section{Vertical distributions of PAH concentrations}

Sediment core data may be useful in evaluating input sources and historical changes in environmental contaminants. In the current study, the mean concentrations of 16 PAHs in sediment cores were compared between the three time periods in the three lakes. The standard deviation values of the concentrations of $16 \mathrm{PAH}$ compounds ranged from 0.8 to $140.0,1.7$ to 90.8 , and 0.2 to 17.3 in $\mathrm{LH}, \mathrm{KQ}$, and WH lakes, respectively. Thus, the variances of individual PAHs were greater over time in core segments of LH and KQ lakes compared to WH Lake.

In general, over 10-year intervals, the concentrations of PAHs were greater in the upper segments of the cores and lower in the bottom segments (Fig. 2). In the three core sediments, there was no significant difference in total PAH concentrations, as well as in most of individual PAH concentrations between the periods 1950s-1960s and 1970s-1980s (Figs. 1, 2). However, significantly greater PAH concentrations were measured in core segments during the period 1990s-2000s than those in periods 1950s-1960s and 1970s-1980s $(p<0.05)$. In the case of LH and KQ lake cores, the PAH concentrations in upper segments of the cores were much higher than those at greater depth (Fig. 2). The concentrations of the majority of PAH compounds were generally low and fairly uniform 
Table 3 Mean concentrations (ng/g dw) of 16 PAHs in core sediments during three time periods from Lianhuan (LH) Lake, Keqin (KQ) Lake, and Wanghua (WH) Lake, Heilongjiang, China, July 2007

\begin{tabular}{|c|c|c|c|c|c|c|c|c|c|c|c|c|}
\hline \multirow[t]{2}{*}{ PAHs } & \multicolumn{3}{|c|}{$1950 \mathrm{~s}-2000 \mathrm{~s}$} & \multicolumn{3}{|c|}{$1950 \mathrm{~s}-1960 \mathrm{~s}$} & \multicolumn{3}{|c|}{$1970 \mathrm{~s}-1980 \mathrm{~s}$} & \multicolumn{3}{|c|}{$1990 \mathrm{~s}-2000 \mathrm{~s}$} \\
\hline & LH $(30)^{*}$ & KQ (22) & WH (25) & LH (10) & KQ (5) & WH (8) & LH (11) & KQ (8) & WH (9) & LH (9) & KQ (9) & WH $(8)$ \\
\hline Nap & $224.3^{\mathrm{a}}$ & $181.1^{\mathrm{b}}$ & $20.4^{\mathrm{c}}$ & $214.8^{\mathrm{a}}$ & $187.9^{\mathrm{a}}$ & $9.6^{\mathrm{b} 3}$ & $248.5^{\mathrm{a}}$ & $173.9^{\mathrm{b}}$ & $17.9^{\mathrm{c} 2}$ & $205.4^{\mathrm{a}}$ & $183.8^{\mathrm{a}}$ & $33.9^{\mathrm{b} 1}$ \\
\hline Acey & $3.5^{\mathrm{a}}$ & $5.0^{\mathrm{a}}$ & $0.4^{\mathrm{b}}$ & $3.9^{\mathrm{a}}$ & $5.0^{\mathrm{a}}$ & $0.5^{\mathrm{b}}$ & $1.1^{\mathrm{b}}$ & $4.3^{\mathrm{a}}$ & $0.7^{\mathrm{b}}$ & $6.1^{\mathrm{a}}$ & $5.7^{\mathrm{a}}$ & $0.1^{\mathrm{b}}$ \\
\hline Ace & $18.7^{\mathrm{a}}$ & $12.7^{\mathrm{b}}$ & $8.3^{\mathrm{c}}$ & $14.2^{\mathrm{a} 2}$ & $9.7^{\mathrm{b} 2}$ & $5.5^{\mathrm{c} 2}$ & $18.1^{\mathrm{a} 12}$ & $12.2^{\mathrm{b} 12}$ & $8.2^{\mathrm{b} 2}$ & $24.3^{\mathrm{a} 1}$ & $14.9^{\mathrm{b} 1}$ & $11.3^{\mathrm{b} 1}$ \\
\hline Flu & $119.7^{\mathrm{a}}$ & $67.5^{\mathrm{b}}$ & $41.4^{\mathrm{b}}$ & $76.1^{\mathrm{a} 2}$ & $49.6^{\mathrm{b} 2}$ & $30.8^{\mathrm{b} 2}$ & $104.2^{\mathrm{a} 2}$ & $57.8^{\mathrm{b} 2}$ & $42.7^{\mathrm{b} 1}$ & $187.1^{\mathrm{a} 1}$ & $86.1^{\mathrm{b} 1}$ & $50.7^{\mathrm{b} 1}$ \\
\hline Phe & $238.6^{\mathrm{a}}$ & $172.3^{\mathrm{ab}}$ & $105.1^{\mathrm{b}}$ & $112.0^{2}$ & $105.0^{2}$ & $89.0^{2}$ & $184.5^{\mathrm{a} 2}$ & $143.5^{\mathrm{ab} 2}$ & $115.1^{\mathrm{b} 1}$ & $445.5^{\mathrm{a} 1}$ & $235.2^{\mathrm{b} 1}$ & $110.0^{\mathrm{b} 1}$ \\
\hline Ant & $18.2^{\mathrm{a}}$ & $10.5^{\mathrm{ab}}$ & $9.8^{\mathrm{b}}$ & $8.8^{2}$ & 9.6 & $23.8^{1}$ & $18.5^{\mathrm{a} 12}$ & $9.1^{\mathrm{b}}$ & $3.0^{\mathrm{b} 2}$ & $28.1^{\mathrm{a} 1}$ & $12.3^{\mathrm{b}}$ & $3.4^{\mathrm{b} 2}$ \\
\hline Fla & $46.2^{\mathrm{b}}$ & $73.4^{\mathrm{a}}$ & $16.5^{\mathrm{c}}$ & $26.2^{\mathrm{b} 2}$ & $43.4^{\mathrm{a} 2}$ & $12.0^{\mathrm{c} 2}$ & $30.1^{\mathrm{b} 2}$ & $58.4^{\mathrm{a} 2}$ & $20.1^{\mathrm{b} 1}$ & $87.9^{\mathrm{a} 1}$ & $103.3^{\mathrm{a} 1}$ & $17.1^{\mathrm{b} 12}$ \\
\hline Pyr & $40.0^{\mathrm{a}}$ & $50.8^{\mathrm{a}}$ & $13.7^{\mathrm{b}}$ & $19.0^{\mathrm{b} 2}$ & $29.6^{\mathrm{a} 2}$ & $10.7^{\mathrm{c}}$ & $29.8^{\mathrm{ab} 2}$ & $40.5^{\mathrm{a} 2}$ & $17.6^{\mathrm{b}}$ & $75.1^{\mathrm{a} 1}$ & $71.8^{\mathrm{a} 1}$ & $12.3^{\mathrm{b}}$ \\
\hline $\mathrm{BaA}$ & $6.1^{\mathrm{b}}$ & $13.6^{\mathrm{a}}$ & $0.7^{\mathrm{c}}$ & $2.9^{\mathrm{b} 2}$ & $6.6^{\mathrm{a}^{2}}$ & $0.4^{\mathrm{c}}$ & $3.3^{\mathrm{b} 2}$ & $9.7^{\mathrm{a}^{2}}$ & $0.8^{\mathrm{c}}$ & $13.2^{\mathrm{b} 1}$ & $21.1^{\mathrm{a} 1}$ & $1.0^{\mathrm{c}}$ \\
\hline Chr & $17.3^{\mathrm{b}}$ & $29.7^{\mathrm{a}}$ & $1.6^{\mathrm{c}}$ & $10.3^{\mathrm{b} 2}$ & $14.3^{\mathrm{a} 2}$ & $0.6^{\mathrm{c} 3}$ & $10.4^{\mathrm{b} 2}$ & $19.8^{\mathrm{a} 2}$ & $1.3^{\mathrm{c} 2}$ & $33.4^{\mathrm{b} 1}$ & $47.1^{\mathrm{a} 1}$ & $3.1^{\mathrm{cl}}$ \\
\hline $\mathrm{BbF}$ & $19.4^{\mathrm{b}}$ & $43.3^{\mathrm{a}}$ & $1.8^{\mathrm{c}}$ & $9.0^{\mathrm{b} 2}$ & $14.6^{\mathrm{a} 2}$ & $0.1^{\mathrm{c} 2}$ & $10.0^{\mathrm{b} 2}$ & $25.7^{\mathrm{a} 2}$ & $0.8^{\mathrm{c} 2}$ & $42.6^{\mathrm{b} 1}$ & $74.9^{\mathrm{a} 1}$ & $4.6^{\mathrm{c} 1}$ \\
\hline $\mathrm{BkF}$ & 1.1 & 0.6 & 0.6 & $0.0^{\mathrm{b} 2}$ & $0.0^{\mathrm{b}}$ & $0.6^{\mathrm{a}}$ & $0.3^{\mathrm{ab} 12}$ & $0.0^{\mathrm{b}}$ & $0.6^{\mathrm{a}}$ & $3.5^{1}$ & 1.6 & 0.4 \\
\hline $\mathrm{BaP}$ & $3.5^{\mathrm{b}}$ & $8.9^{\mathrm{a}}$ & $0.5^{\mathrm{c}}$ & $0.6^{\mathrm{b} 2}$ & $1.8^{\mathrm{a} 2}$ & $0.2^{\mathrm{c} 2}$ & $1.3^{\mathrm{b} 2}$ & $5.6^{\mathrm{a} 2}$ & $0.4^{\mathrm{b} 2}$ & $9.5^{\mathrm{b} 1}$ & $15.7^{\mathrm{a} 1}$ & $0.9^{\mathrm{c} 1}$ \\
\hline IcdP & $6.1^{\mathrm{b}}$ & $12.0^{\mathrm{a}}$ & $0.7^{\mathrm{c}}$ & $1.0^{\mathrm{b} 2}$ & $1.9^{\mathrm{a} 2}$ & $0.1^{\mathrm{c} 2}$ & $2.0^{\mathrm{b} 2}$ & $6.0^{\mathrm{a} 2}$ & $0.1^{\mathrm{b} 2}$ & $16.8^{\mathrm{a} 1}$ & $23.1^{\mathrm{a} 1}$ & $1.9^{\mathrm{b} 1}$ \\
\hline DahA & $1.6^{\mathrm{b}}$ & $2.4^{\mathrm{a}}$ & $0.9^{c}$ & $0.9^{2}$ & $1.1^{2}$ & 0.8 & $1.1^{\mathrm{b} 2}$ & $1.7^{\mathrm{a} 2}$ & $0.9^{\mathrm{b}}$ & $2.8^{\mathrm{a} 1}$ & $3.8^{\mathrm{a} 1}$ & $0.9^{\mathrm{b}}$ \\
\hline BghiP & $2.7^{\mathrm{b}}$ & $10.0^{\mathrm{a}}$ & $0.1^{\mathrm{b}}$ & $0.0^{\mathrm{b} 2}$ & $0.6^{\mathrm{a} 2}$ & $0.0^{\mathrm{b} 2}$ & $0.3^{\mathrm{b} 2}$ & $3.7^{\mathrm{a} 2}$ & $0.0^{\mathrm{b} 2}$ & $8.6^{\mathrm{b} 1}$ & $20.8^{\mathrm{a} 1}$ & $0.5^{\mathrm{c} 1}$ \\
\hline
\end{tabular}

Concentration means followed by different superscript letters ( $\mathrm{a}, \mathrm{b}$, and $\mathrm{c}$ ) are significantly different (ANOVA, $p<0.05$ ) between the three lakes in the periods of 1950s-2000s, 1950s-1960s, 1970s-1980s, and 1990s-2000s, respectively; concentration means followed by different superscript numbers $(1,2$, and 3 ) are significantly different (ANOVA, $p<0.05$ ) between the three periods of 1950s-1960s, 1970s-1980s, and 1990s2000 s in LH, KQ, and WH lakes, respectively

* Numbers of core segments
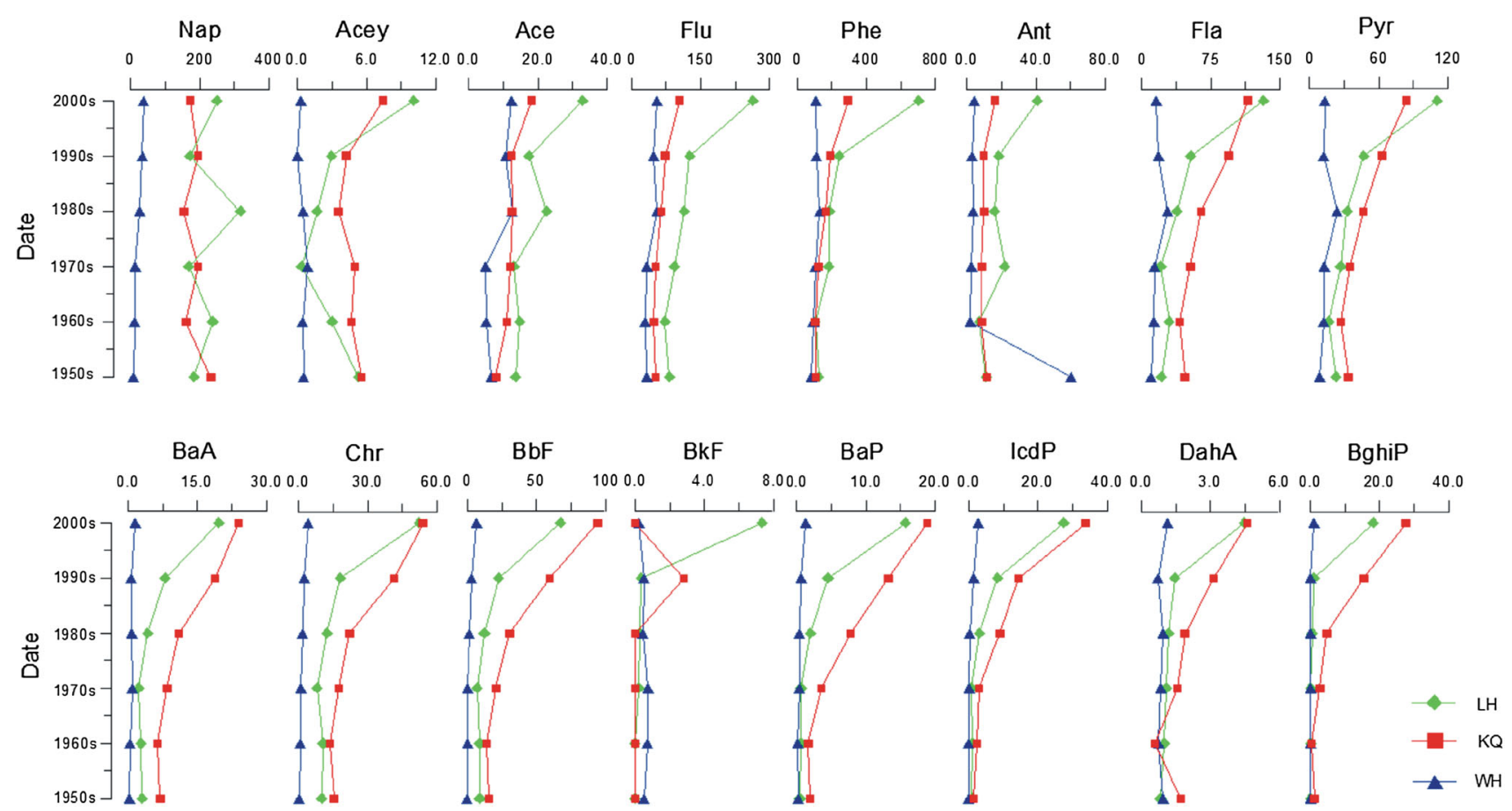

Fig. 2 Vertical distributions of mean concentrations (ng/g) of individual PAH compounds of every 10 years in the core sediments from Lianhuan (LH) Lake, Keqin (KQ) Lake, and Wanghua (WH) Lake, Heilongjiang, China, July 2007 
before the 1960s, most of which were the lowest concentrations measured in the core sediments. Since the 1970s, the concentrations of most PAHs increased markedly and the greatest PAH concentrations were measured during recent years, especially for HMW PAHs in LH and KQ lakes.

In 1950s and 1960s, the concentrations of the 16 measured PAHs in the three lakes were relatively stable and lower than those in more recent time periods, especially in WH Lake. This probably reflected reduced anthropogenic impacts and pollution of surface sediments during this time period. During the time period 1970s and 1980s, the continuous increase in PAH concentrations in the three lakes suggested greater contaminants from atmospheric input and overland runoff into lake sediments. Though there was no significant difference in PAH sources compared with the previous time period in each lake, the significant increase in HMW PAHs, especially in KQ Lake, indicated a change in the fuel consumption from wood to coal and liquid fossil fuel. During the time periods 1990s and 2000s, PAH concentrations increased continuously; in particular, most HMW PAHs increased more sharply since the 1990s in the three lakes. The main source of PAHs in the three lakes became similar, indicating liquid fossil fuel as the major energy source. Human activities, as the most important factor, affect the concentrations and sources of PAHs in the environment by increasing the PAH emissions, in particular in urban areas. Take Daqing area as an example, the population size was only 205,000 in 1960 as reported by local statistical bureau in Daqing when the Daqing Oil Field was established, and the influences of anthropogenic activities on lakes were very little due to the small population size. With the development of industrialization and urbanization of the City of Daqing, the population size increased to $1,025,900$ in 1990 . Therefore, the lake sediments were affected by anthropogenic activities much more significantly.

\section{PAH toxicological assessment}

Sediments are the most important sink for PAHs in the aquatic environment due to their high hydrophobicity and strong particulate-oriented behaviors (Kannan et al. 2005; Colombo et al. 2006; Guo et al. 2011). As a group of hazardous materials, PAHs in sediments can directly or indirectly affect aquatic organisms (Guo et al. 2011). To evaluate the concentrations of PAHs from an ecotoxicological perspective, the PAH concentrations from the three core sediments were compared with threshold effects concentrations: effects range low (ERL) and effects range median (ERM) (Long et al. 1995).

Since the 1950s, in all segments of the sediment cores from the three lakes evaluated, the concentrations of total PAHs and most individual PAH compounds were far less than their respective ERL values. The range of Flu concentrations in LH, KQ, and WH lakes was 44.5-357.5, 20.9-128.3, and $23.7-65.8 \mathrm{ng} / \mathrm{g}$, respectively, which were between the ERL and ERM values ( $\geq 19$ and $<540 \mathrm{ng} / \mathrm{g}$ ). Concentrations of Nap and Ace in most segments of LH and KQ lakes were below the respective ERM, but above the respective ERL (Fig. 3).

During the 1950s and 1960s, for LH and KQ lakes, concentrations of Nap in most segments were higher than the ERL value (160 $\mathrm{ng} / \mathrm{g})$, but lower than the ERM value $(2,100 \mathrm{ng} / \mathrm{g})$. Concentrations of Ace were approximate to the ERL value $(16 \mathrm{ng} / \mathrm{g})$ in LH Lake and lower than the ERL values in KQ Lake. During the 1970s-1980s, especially in the 1980s, concentrations of Nap and Ace in most
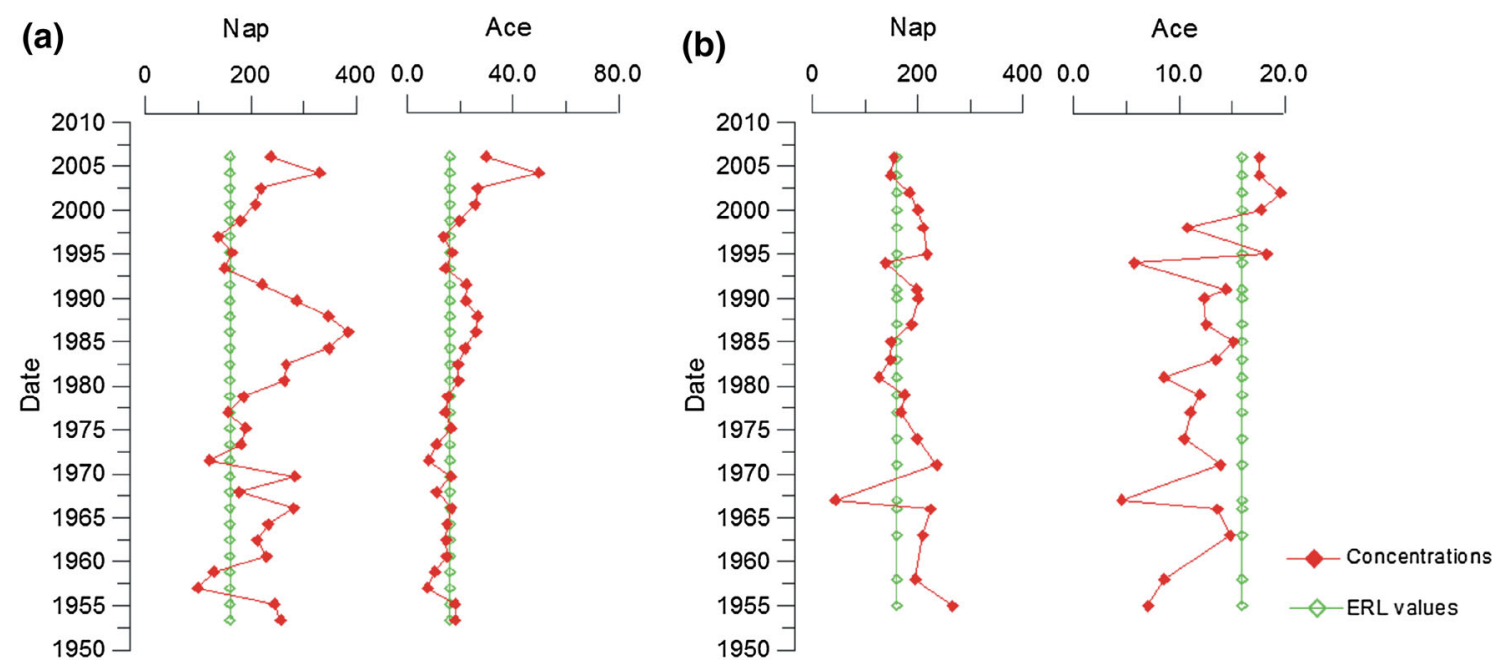

Fig. 3 Risk for effects range low (ERL) to Nap and Ace in sediments from Lianhuan (LH) Lake (a) and Keqin (KQ) Lake (b), Heilongjiang Province, China, from the 1950s-2000s 
segments of the sediment core from LH Lake were much greater than the respective ERL values, but lower than the ERM. Concentrations of Nap in KQ Lake were lower than those in LH Lake, but they were also above the ERL value, while Ace concentrations were lower than ERL values. For the time period 1970s-1980s, especially since the end of 1990s, concentrations of Nap and Ace in most segments of the sediment core from $\mathrm{KQ}$ and $\mathrm{LH}$ lakes were much greater than the respective ERL values (Fig. 3).

The PAH toxicological assessment in the current study implied that occasionally adverse biological effects can occur from exposure to Flu, Nap, and Ace in LH and KQ lakes. However, of greater concern is the rapid increase in HMW PAH compounds since the 1990s with potential carcinogenic, genotoxic, and immunotoxic effects on wildlife and humans. Further investigations evaluating the increases in HMW PAHs in lake sediments and bioaccumulation in aquatic organisms are currently being developed.

\section{Source apportionment of PAHs by diagnostic ratios}

The compositional pattern of PAH compounds was used to distinguish the possible sources of PAHs from different anthropogenic activities. The predominant PAHs in the three lakes were in good agreement with the findings of other lakes in China (Zhang et al. 2011; Liu et al. 2009; Guo et al. 2011), despite the large differences in the concentrations measured in different lakes. It is generally accepted that Nap and Phe were the major PAHs produced during the combustion of solid fossil fuels or burning of wood and coal (Lake et al. 1979; Laflamme and Hites 1978; Li et al. 2009; Hu et al. 2010).

To further determine the contributions of the sources of anthropogenic PAHs to contaminant loadings, Fla/ $(\mathrm{Fla}+\mathrm{Pyr})$ against $\mathrm{BaA} /(\mathrm{BaA}+\mathrm{Chr})$ ratios were evaluated (Hu et al. 2010) (Fig. 4). During the 1950s-2000s, the values of $\mathrm{Fla} /(\mathrm{Fla}+\mathrm{Pyr})$ and $\mathrm{BaA} /(\mathrm{BaA}+\mathrm{Chr})$ in all segments of KQ Lake ranged from 5 to 7 and from 2 to 3.5 , respectively, indicating that the main input sources were from liquid fossil fuel (vehicle and crude oil) and coal and wood combustions in this lake. During the 1950s-1960s time period, the $\mathrm{Fla} /(\mathrm{Fla}+\mathrm{Pyr})$ ratio was $<0.4$ in several segments of LH Lake, and BaA/ $(\mathrm{BaA}+\mathrm{Chr})$ ratio in several segments of WH Lake was $<0.2$, suggesting petroleum source inputs into these lakes during this time period. Source of liquid fossil fuel was also detected in several segments of LH Lake. The greater values of $\mathrm{BaA} /(\mathrm{BaA}+\mathrm{Chr})$ and $\mathrm{Fla} /(\mathrm{Fla}+\mathrm{Pyr})$ ratios in WH Lake indicated the main combustions of wood and coal. During 1970s-1980s, the sources of PAHs in LH and WH lakes were consistent with those were found, respectively, in the previous period.
Furthermore, source of petroleum combustion was also detected in these two lakes. During the 1990s-2000s, PAHs in most segments of LH and WH lakes were from liquid fossil fuel and coal and wood combustion sources. Only a few segments of LH and WH lakes were from petroleum combustion source and petroleum source during 1990s-2000s. Historical data indicate a gradual trend away from combustion (wood and coal) and petroleum (oil) as the major polluting energy sources to mixed sources of energy (liquid petroleum and combustion) as the major contributors of PAHs to the lake sediments.

Sources of PAHs between rural and urban areas

In the current study, the sources of the PAHs were significantly different between an agricultural rural area and an industrial urban area. Wanghua Lake, located in a rural area, had significantly lower concentrations of total PAHs compared to LH and KQ lakes, located in an industrial urban area. Energy use in the vicinity of all three study sites includes combustions of biomass, wood, and coal, which are heavily used for domestic heating in northeast China in the long winter. Moreover, a typical industrial urban source of liquid fossil fuel combustion was identified in LH and KQ lakes, which are adjacent to the Cities of Daqing and Qiqihar, respectively. Both cities are highly developed with industry and have high vehicular and population densities. The greater PAH concentrations measured in sediment cores from LH and KQ lakes compared to WH Lake can be explained by the fact that LH and KQ lakes have a greater density of vehicular traffic and humans and are more heavily contaminated by urban and industrial discharges from the cities.

The histories of changing energy use around the three study lakes are reflected in the profiles of the changing PAHs in the sediment core samples from the 1950s to 2000s. The overall histories of PAHs from the 1950s to the 2000s were distinct in the three lakes though similar trends were observed. The concentrations of PAHs changed little with depth in WH Lake, suggesting that the contamination levels are relatively steady over time in rural area. However, PAH concentrations changed more sharply in LH and KQ lakes, indicating a greater increase in pollutants in urban and industrial areas compared with the rural area. The increase in HMW PAHs during more recent time periods is a reminder of the increase in abundance of different pyrogenic sources, probably from liquid fossil fuel combustion and vehicle emission (Liu et al. 2009). The two lakes located in the industrial areas were located near the S201 Provincial Highway, and the high traffic volumes may contribute to the high concentrations of HMW PAHs in these lake sediments. 
Fig. 4 Isomeric ratios $\mathrm{BaA} /$

$(\mathrm{BaA}+\mathrm{Chr})$ versus $\mathrm{Fla} /$

$(\mathrm{Fla}+\mathrm{Pyr})$ identifying sources of PAHs in sediments from Lianhuan(LH) Lake, Keqin (KQ) Lake, and Wanghua (WH) Lake, Heilongjiang Province,

China, during three time periods (a 1950s-1960s; b 1970s1980s; c 1990s-2000s)
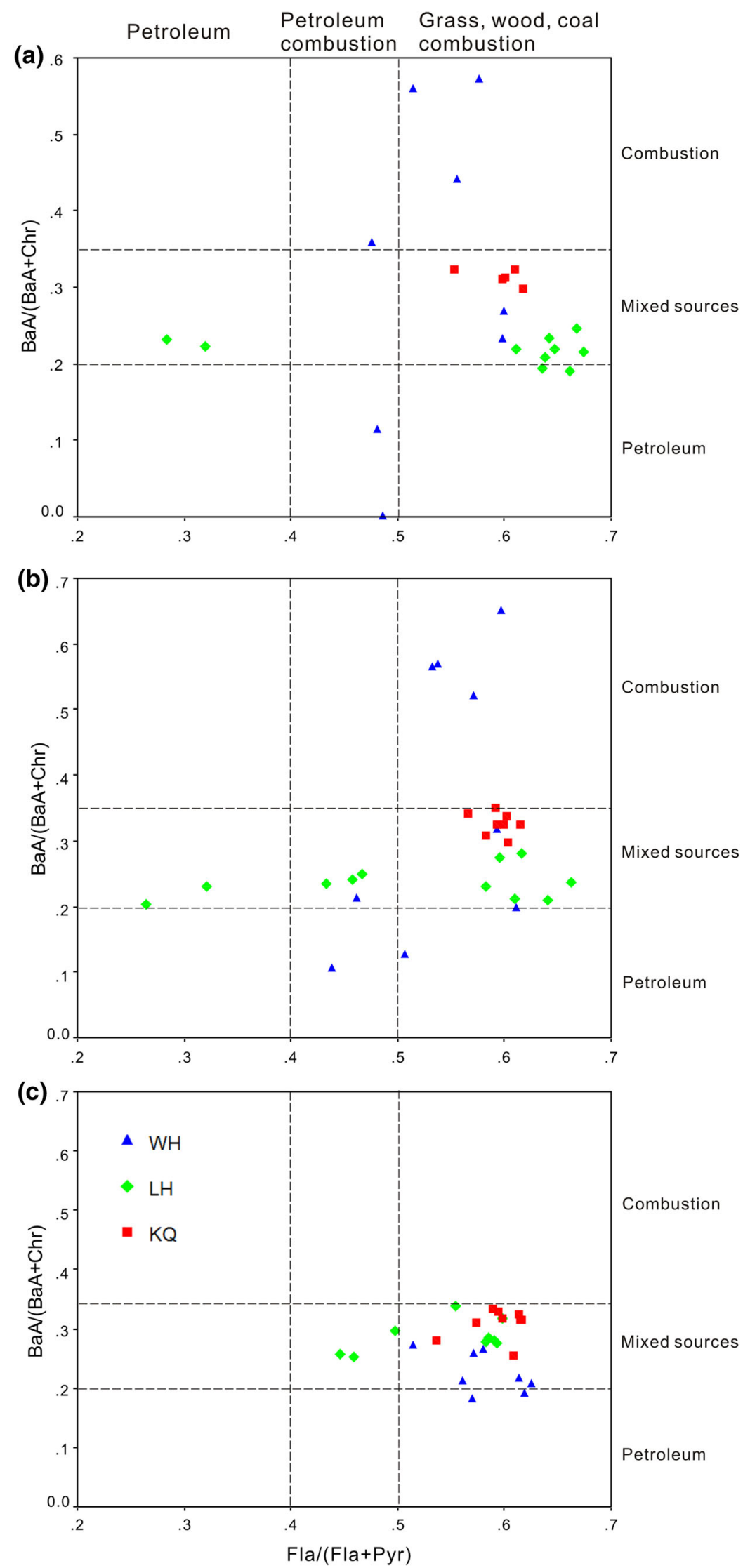
Impacts of oil production on three representative areas

The ratios of several samples in LH and WH lakes were consistent with sources of petroleum input, which is consistent with the surrounding land use. Both lakes were located next to oil drilling platforms of the Daqing Oil Field, and spillage of petroleum from the processes of drilling, transportation, and extraction of crude oil likely occurred during the oil development process. However, KQ Lake, located near the Qiqihar industrial region and with no oil field influence, has not been contaminated by petroleum and its products. Similarly, White et al. (2005) reported ratios of Fla to Pyr ranging from 0.4 to 0.9 in core sediments influenced by the spilling of No. 2 fuel oil in Wild Harbor, West Falmouth.

During the time periods 1990s and 2000s, the main source of PAHs in sediment core samples from all three lakes studied became similar and reflected the increased use of liquid fossil fuels as an energy source. The decrease in petroleum source measured in sediments from LH and WH lakes since the early 1990s may be related to decreased petroleum leakage during drilling and transportation resulting from improved techniques associated with oil exploitation and extraction.

\section{Conclusion}

Concentrations of PAHs measured in sediment cores indicate that sediments in lakes located in rural oil-producing areas have less PAH pollution than sediments in lakes from industrialized areas, regardless of whether the industrial lakes are associated with oil production or not. From 1950s to the 2000s, the lowest PAH concentrations were measured in sediments from WH Lake located in a rural oil-producing area, compared to concentrations measured in sediments from LH and KQ lakes, both of which were located in industrial areas, one with and one without associated oil production. Regardless of the surrounding land use, PAH profiles indicate that there has been a gradual shift from combustion and petroleum energy sources to liquid fossil fuel energy sources from the 1950 s to 2000 s in all three lakes studied. Environmental risk analysis indicates that the risk in WH Lake was low, while the risk in LH and KQ lakes was moderate, primarily resulting from increased concentrations of Nap and Ace. However, a more serious pending problem appears to be the rapid increase in HMW PAHs that were measured in sediments from LH and KQ lakes during the 1990s-2000s. Continuous monitoring of sediments and appropriate regulations are recommended for these lakes.
Acknowledgments This study was financially supported by the key National Natural Science Foundation of China (No. 41030743), the Science and Technology Innovative Programs Foundation of Higher Education of Heilongjiang Province (No. 2010td10), and Graduate Innovative Programs Foundation of Heilongjiang Province (No. YJSCX2011-394HLJ).

\section{References}

Colombo JC, Cappelletti N, Lasci J, Migoya MC, Speranza E, Skorupka CN (2006) Sources, vertical fluxes, and equivalent toxicity of aromatic hydrocarbons in coastal sediments of the Río de la Plata Estuary, Argentina. Environ Sci Technol 40:734-740

Countway RE, Dickhut RM, Canuel EA (2003) Polycyclic aromatic hydrocarbon $(\mathrm{PAH})$ distributions and associations with organic matter in surface waters of the York River, VA Estuary. Org Geochem 34(2):209-224

Froehner S, Dombroski LF, Machado KS, Fernandes CS, Bessa M (2012a) Estimation of bioavailability of polycyclic aromatic hydrocarbons in river sediments. Int $\mathrm{J}$ Environ Sci Technol 9:409-416

Froehner S, de Souza DB, Machado KS, Falcao F, Fernandes CS, Bleninger T (2012b) Impact of coal tar pavement on polycyclic hydrocarbon distribution in lacustrine sediments from nontraditional sources. Int J Environ Sci Technol 9:327-332

Guo JY, Wu FC, Zhang L, Liao HQ, Zhang RY, Li W, Zhao XL, Chen SJ, Mai BX (2011) Screening level of PAHs in sediment core from Lake Hongfeng, southwest China. Arch Environ Contam Toxico 160(4):590-596

Hakan P, Duran K, Savas A, Leyla T, Mithat B (2004) Ecological risk assessment using trace elements from surface sediments of Izmit Bay (Northeastern Marmara Sea) Turkey. Mar Pollut Bull 489:46-53

Hu NJ, Shi XF, Liu JH, Huang P, Liu YG, Liu Y (2010) Concentrations and possible sources of PAHs in sediments from Bohai Bay and adjacent shelf. Environ Earth Sci 60:1771-1782

Inengite AK, Oforka NC, Osuji Leo C (2013) Source identification of polycyclic aromatic hydrocarbons in sediments of a creek around a flow station. Int J Environ Sci Technol 10:519-532

Kannan K, Johnson-Restrepo B, Yohn SS, Giesy JP, Long DT (2005) Spatial and temporal distribution of polycyclic aromatic hydrocarbons in sediments from Michigan Inland Lakes. Environ Sci Technol 39:4700-4706

Kumar V, Kothiyal NC (2011) Distribution behavior of polycyclic aromatic hydrocarbons in roadside soil at traffic intercepts within developing cities. Int J Environ Sci Technol 8(1):63-72

Laflamme RE, Hites RA (1978) The global distribution of polycyclic aromatic hydrocarbons in recent sediments. Geochim Cosmochim Acta 42:289-303

Lake JL, Norwood C, Dimock C, Brown R (1979) Origins of polycyclic aromatic hydrocarbons in estuarine sediments. Geochim Cosmochim Acta 43:1847-1854

Li HL, Gao H, Zhu C, Li GG, Yang F, Zheng YG, Lian J (2009) Spatial and temporal distribution of polycyclic aromatic hydrocarbons (PAHs) in sediments of the Nansi Lake, China. Environ Monit Assess 154:469-478

Liu Y, Chen L, Huang QH, Li WY, Tang YJ, Zhao JF (2009) Source apportionment of polycyclic aromatic hydrocarbons (PAHs) in surface sediments of the Huangpu River, Shanghai, China. Sci Total Environ 407:2931-2938

Liu LY, Wang JZ, Wei GL, Guan YF, Wong CS, Zeng EY (2012) Sediment records of polycyclic aromatic hydrocarbons (PAHs) in the continental shelf of China: implications for evolving anthropogenic impacts. Environ Sci Technol 46:6497-6504 
Long ER, MacDonald DD, Smith SJ, Calder FD (1995) Incidence of adverse biological effects within ranges of chemical concentrations in marine and estuarine sediments. Environ Manag 19:81-97

Luo XJ, Chen SJ, Mai BX, Sheng GY, Fu JM, Zeng EY (2008) Distribution, source apportionment, and transport of PAHs in sediments from the Pearl River Delta and the northern south China Sea. Arch Environ Contam Toxicol 55:11-20

Rao PS, Ansari MF, Pipalatkar P, Kumar A, Nema P, Devotta S (2008) Measurement of particulate phase polycyclic aromatic hydrocarbons (PAHs) around a petroleum refinery. Environ Monit Assess 137:387-392

Salam MA, Shirasuna Y, Hirano K, Masunaga S (2011) Particle associated polycyclic aromatic hydrocarbons in the atmospheric environment of urban and suburban residential area. Int $\mathbf{J}$ Environ Sci Technol 8(2):255-266

Sun L, Zang SY (2012) History of fuel consumption inferred from polycyclic aromatic hydrocarbons in sediments from the south Lianhuan Lake, northeast China. Bull Environ Contam Toxicol 88:1027-1032
Sun L, Zang SY, Xiao HF (2011) Historical record and source apportionment of polycyclic aromatic hydrocarbons in the Lianhuan Lake sediments. Ecotoxicology 20:951-958

USEPA (1996) Test methods for evaluating solid waste, physical/ chemical methods SW-846. Washington, DC, USA: Office of solid waste and emergency response

White HK, Xu L, Lima ALC, Eglinton TI, Reddy CM (2005) Abundance, composition, and vertical transport of PAHs in marsh sediments. Environ Sci Technol 39:8273-8280

Zhang Y, Lu Y, Xu J, Yu T, Zhao WZ (2011) Spatial distribution of polycyclic aromatic hydrocarbons from Lake Taihu, China. Bull Environ Contam Toxicol 87:80-85

Zhao ZY, Chu YL, Gu J-D (2012a) Distribution and sources of polycyclic aromatic hydrocarbons in sediments of the Mai Po Inner Deep Bay Ramsar Site in Hong Kong. Ecotoxicology 21:1743-1752

Zhao ZY, Zhuang YX, Gu J-D (2012b) Abundance, composition and vertical distribution of polycyclic aromatic hydrocarbons in sediments of the Mai Po Inner Deep Bay of Hong Kong. Ecotoxicology 21:1734-1742 